\title{
Association between green tea intake and risk of gastric cancer: a systematic review and dose-response meta-analysis of observational studies
}

\author{
Yanhong Huang ${ }^{1} \dagger$, Hongru Chen ${ }^{1} \dagger$, Liang Zhou ${ }^{1}{ }^{2}$, Gaoming $\mathrm{Li}^{1}$, Dali $\mathrm{Yi}^{1}$, Yanqi Zhang ${ }^{1}$, \\ Yazhou Wu ${ }^{1}$, Xiaoyu Liu ${ }^{1}$, Xiaojiao Wu ${ }^{1}$, Qiuyue Song ${ }^{1}$, Ling Liu ${ }^{1}$ and Dong $\mathrm{Yi}^{1}{ }^{1, *}$ \\ 'Department of Health Statistics, College of Preventive Medicine, Third Military Medical University, Chongqing \\ 400038, People's Republic of China: ${ }^{2}$ Department of Ninth Research Institute of Field Surgery, Third Military \\ Medical University, Chongqing, People's Republic of China
}

Submitted 19 May 2016: Final revision received 28 June 2017: Accepted 7 July 2017: First published online 5 0ctober 2017

\begin{abstract}
Objective: To examine and quantify the potential dose-response relationship between green tea intake and the risk of gastric cancer.

Design: We searched PubMed, EMBASE, Web of Science, CBM, CNKI and VIP up to December 2015 without language restrictions.

Setting: A systematic review and dose-response meta-analysis of observational studies. Subjects: Five cohort studies and eight case-control studies.

Results: Compared with the lowest level of green tea intake, the pooled relative risk $(95 \% \mathrm{CI})$ of gastric cancer was $1.05\left(0 \cdot 90,1.21, I^{2}=20 \cdot 3 \%\right)$ for the cohort studies and the pooled OR (95\% CI) was $0.84\left(0.74,0.95, I^{2}=48.3 \%\right)$ for the case-control studies. The pooled relative risk of gastric cancer was 0.79 $\left(0.63,0.97, I^{2}=63.8 \%\right)$ for intake of 6 cups green tea/d, $0.59(0.42,0.82$, $\left.I^{2}=1.0 \%\right)$ for 25 years of green tea intake and $7.60\left(1.67,34 \cdot 60, I^{2}=86.5 \%\right)$ for drinking very hot green tea.

Conclusions: Drinking green tea has a certain preventive effect on reducing the risk of gastric cancer, particularly for long-term and high-dose consumption. Drinking too high-temperature green tea may increase the risk of gastric cancer, but it is still unclear whether high-temperature green tea is a risk factor for gastric cancer. Further studies should be performed to obtain more detailed results, including other gastric cancer risk factors such as smoking and alcohol consumption and the dose of the effective components in green tea, to provide more reliable evidence-based medical references for the relationship between green tea and gastric cancer.
\end{abstract}

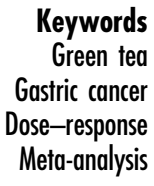

Keywords Gastric cancer Dose-response
Green tea is derived from the plant Camellia sinensis and is the second most popular beverage worldwide, behind only drinking-water ${ }^{(1)}$. Because green tea has not been fermented, most of its natural phytochemicals are preserved; of which tea polyphenols represent the highest proportion $^{(2)}$. Tea polyphenols is a mixture of polyhydroxy phenolic compounds present in tea (especially green tea) whose main components are catechins (i.e. epigallocatechingallate, epigallocatechin and epicatechin-gallate), flavones, flavonols and anthocyanidins ${ }^{(3)}$. Several animal studies ${ }^{(4-6)}$

$\dagger$ Yanhong Huang and Hongru Chen contributed equally to this work. and reviews ${ }^{(7-9)}$ have found that tea polyphenols have a variety of biological effects, including antimutation, anticancer, antioxidation, bacteriostatic and bactericidal actions, and protective effects on the nervous and cardiovascular systems. These results further promoted the worldwide popularity of green tea.

The stomach is a major organ of the digestive tract and an essential place for food after entering the body. During the digestive process, food often stays in the stomach for a long time; thus, food has extensive direct or indirect contact with the stomach wall (especially the cells of the gastric mucosa layer). A variety of chemical constituents in 
food have various impacts on the stomach microenvironment or directly on the cells of the gastric mucosa layer ${ }^{(10)}$. The occurrence of gastric cancer is closely related to lifestyle, environmental and genetic factors, such as drinking, smoking, high-salt diet, diet lacking fresh vegetables and fruits, Helicobacter pylori infection, and family history of gastric cancer ${ }^{(11-13)}$.

Gastric cancer is one of the most common gastrointestinal malignancies ${ }^{(14)}$. The incidence rate of gastric cancer in 2012 ranked it as the fifth most common cancer worldwide, following lung cancer, breast cancer, colorectal cancer and prostate cancer $^{(14)}$. More than $70 \%$ of the diagnosed cases originated from developing countries, and half of the cases were from East Asia (especially China). Gastric cancer ranked third in terms of mortality ${ }^{(14,15)}$. Radical surgery is currently the most effective physical treatment. The prognosis of patients with gastric cancer is poor, making gastric cancer is a serious public health problem ${ }^{(16,17)}$. Many epidemiological studies on the correlation between green tea and the risk of gastric cancer have been reported, but their results are inconsistent ${ }^{(18-33)}$. A large number of casecontrol studies ${ }^{(18,21,28,30)}$ reported that drinking green tea reduced the risk of gastric cancer, but a large number of case-control $^{(20,23,26,29)}$ and cohort studies ${ }^{(19,22,24,25,27)}$ also reported that drinking green tea had no effect on the incidence of gastric cancer. Data regarding the risk of gastric cancer for different doses of green tea exposure are also inconsistent. Green tea consumption may have a doseresponse relationship with the occurrence of gastric cancer. Therefore, we conducted a dose-response meta-analysis of observational studies to quantify the correlation between green tea intake and the risk of gastric cancer.

\section{Methods}

\section{Literature search strategy}

Chinese and international published studies on the correlation between the consumption of green tea and the occurrence of gastric cancer were collected by searching PubMed, EMBASE, Web of Science, CBM, CNKI and VIP databases. The retrieval time was from the establishment of the database to December 2015. Information from related conferences was manually retrieved from the library of the Third Military Medical University. The keywords for the search were 'green tea', 'camellia sinensis', 'gastric', 'stomach', 'cancer', 'neoplasm' and 'tumor'. The detailed search strategy for PubMed is provided in the online supplementary material, Table S1.

\section{Study selection}

Studies which met the following eligibility criteria were included: (i) cohort study, case-control study or nested case-control study; (ii) gender and age of the study participants were not restricted, and patients with primary gastric cancer were diagnosed based on the relevant international diagnostic criteria; (iii) the exposure of interest was intake of green tea (needed to be brewed and not blended drinks) and other lifestyle habits (i.e. smoking and drinking), excluding tea beverages and pre-made tea products; (iv) baseline data availability for the control group was the same as for the study group; and (v) for dose-response analysis, the number of cases, participants or person-years for each category of green tea intake (or data available to calculate them), and OR, relative risk (RR), hazard ratio (HR) and 95\% CI were also provided. If data were duplicated in more than one study, the study with the largest number of cases was included.

\section{Data extraction and quality assignment}

In accordance with the inclusion and exclusion criteria, two investigators (Y.H.H. and H.R.C.) independently screened the studies, extracted the data and evaluated the quality. In the case of disagreement, the decision for inclusion of a study was made through discussion or by a third investigator (L.Z.).

The data extracted from the contents included: (i) general information (first author, year of publication, age, sample source and observation year); and (ii) outcome indicators (the number of cases, participants or person-years for each category of green tea intake, multivariate-adjusted effect size and 95\% CI after adjustment, and the corresponding adjustment factors).

The quality of the included studies was evaluated using the Newcastle-Ottawa Scale (NOS) ${ }^{(34)}$. The full score on the NOS is 9, and the included studies were evaluated based on the three aspects of selection, comparability and outcome $^{(35)}$. Studies with NOS scores of 7,8 or 9 were regarded as high quality; other scores were considered to indicate low quality.

\section{Statistical analysis}

Statistical heterogeneity was assessed using the $I^{2}$ statistic and $\chi^{2}$ test. Heterogeneity was confirmed with a significance level of $P \leq 0 \cdot 10$. For the $I^{2}$ metric, we defined low, moderate and high $I^{2}$ values to be 25,50 and $75 \%$, respectively.

If statistical heterogeneity was evident across the studies $\left(I^{2}>50 \%\right)$, a random-effects model was selected to estimate the overall OR (for case-control studies) or RR (for cohort studies) and 95\% CI for the highest $v$. the lowest dose of green tea intake ${ }^{(36)}$. Otherwise, a fixed-effects model was applied. If the studies reported the results separately for men and women, we combined the genderspecific estimates using a fixed-effects model to generate an estimate for both genders combined. The statistical analyses were performed using the statistical software package Stata version 11.0.

We used a random-effects model to calculate the summary effect size and the $95 \%$ CI for the non-linear doseresponse analysis. We evaluated a potential linear curve for dose, years and temperature of green tea intake and the risk 
of gastric cancer using restricted cubic splines with three knots at the 10th, 50th and 90th percentiles of the distribution $^{(37)}$. The method requires that the distributions of cases and person-years or non-cases and the effect size with the variance estimates for at least three quantitative exposure categories are known. We estimated the distribution of cases or person-years in studies that did not report these variables but reported the total number of cases and person-years (supplemental Material 1, available at Annals of Oncology online) ${ }^{(38)}$. If the study reported the mean or median of green tea intake, these values were directly used in our analysis; if the values were not reported, the midpoint of each dose range was used as the mean intake. If the lowest dose group had an open interval, 0 was assigned as the lower limit of the dose range. If the highest dose group had an open interval, the same interval length as the next group was assigned. The dose of green tea intake for all studies was unified into the same unit (cups/d). When the dose of the green tea intake was reported in grams, millilitres or batches, it was converted into cups $(1 \mathrm{~g}=100 \mathrm{ml}=1$ batch $=1$ cup $)^{(24)}$. When the unit of time was reported as annually, monthly or weekly, it was converted to daily (multiplied by $1 / 365,1 / 30$ and $1 / 7$, respectively). The original studies did not provide the specific drinking temperature of the green tea; instead, five grades of green tea consumption (undrinkable, cool $\left(<35^{\circ} \mathrm{C}\right)$, warm $\left(35-46.9^{\circ} \mathrm{C}\right)$, hot $\left(47-54.9^{\circ} \mathrm{C}\right)$ and very hot $\left.\left(55-67^{\circ} \mathrm{C}\right)\right)^{(39)}$ were assigned and given values of $0,1,2,3$ and 4 , respectively, for the dose-response meta-analysis. The meta-analysis of the dose-response relationship was conducted using the software R 3.1.2 (package: mvmeta, dosresmeta, Hmisc, survival, SparseM and rms).

Potential publication bias was assessed by the application of funnel plots, Egger's linear regression test and Begg's rank correlation test at the $P<0 \cdot 10$ level of significance. A sensitivity analysis was conducted to investigate the influence of a single study on the risk estimate by omitting each study individually. These analyses were performed using Stata version 11.0.

\section{Results}

\section{Literature search}

We obtained 495 studies during our initial electronic search. After screening the titles and/or abstracts, 186 studies were excluded because they had no relevance to our analysis. After screening the full text, we excluded fourteen studies with no data available, one cross-sectional study, three clinical trials, six reviews and two repeated articles. Finally, thirteen studies satisfying the eligibility criteria met the inclusion criteria for our meta-analysis (Fig. 1) ${ }^{(18-30)}$.

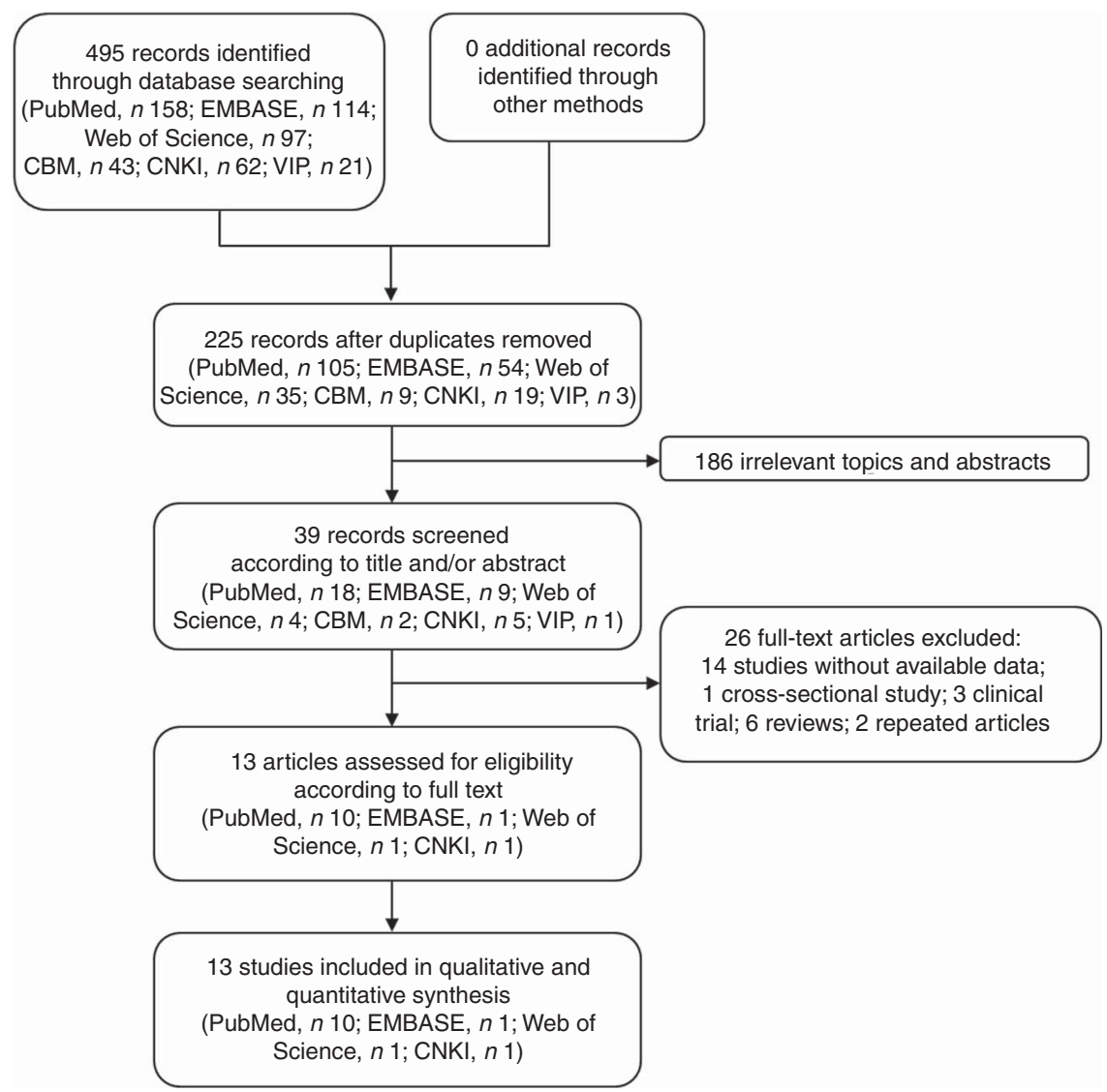

Fig. 1 Flow diagram of the literature search and selection of studies for the current meta-analysis on green tea intake and risk of gastric cancer 


\section{Study characteristics}

The present review included a total of thirteen observational studies, with five cohort studies ${ }^{(19,22,24,25,27)}$ and eight case-control studies ${ }^{(18,20,21,23,26,28-30)}$. A total of 6627 patient cases were involved with sample sizes ranging from 400 to 199748 , ages ranging from 18 to 80 years and observation periods ranging from 5 months to 19 years. The related factors adjusted for included age, gender, smoking and alcohol consumption (Table 1).

\section{Quality assessment}

The quality of the included studies was assessed using the NOS. The scores of the cohort studies were relatively high, with scores of 7-9 for all five studies that were considered high quality. For the case-control studies, the NOS score of one study fell in the range of 0-6 (low quality), whereas the other seven studies scored 7-9 (high quality; see online supplementary material, Table S2).

\section{High v. low intake meta-analysis}

All five cohort studies were included in the correlation analysis of the high $v$. low dose of green tea and the risk of gastric cancer $^{(19,22,24,25,27)}$. The pooled relative risk was 1.05 (95\% CI $0.90,1.21$ ), with low evidence of heterogeneity $\left(I^{2}=20 \cdot 3 \%, P=0 \cdot 286\right)$. There was no significant correlation between green tea and gastric cancer (Fig. 2).

All eight case-control studies were included in the correlation analysis of the high $v$. low dose of green tea and the risk of gastric cancer ${ }^{(18,20,21,23,26,28-30)}$. The pooled relative risk was 0.84 (95\% CI $0.74,0.95)$ with moderate evidence of heterogeneity $\left(I^{2}=48 \cdot 3 \%, P=0.060\right)$. Drinking a high dose of green tea reduced the risk of gastric cancer by $26 \%$ (Fig. 3).

\section{Non-linear dose-response analysis}

All eight case-control studies were included in the nonlinear dose-response analysis for the dose of green tea intake and the risk of gastric cancer ${ }^{(18,20,21,23,26,28-30)}$. When the green tea intake was 4 cups/d or less, no nonlinear relationship between the intake of green tea and the risk of gastric cancer was found (OR $=0 \cdot 77,95 \% \mathrm{CI} 0.59$, $1 \cdot 00, I^{2}=63.8 \%$ for 4 cups (approximately $4 \mathrm{~g}$ ) of green tea intake daily). However, when the intake of green tea was 4-6 cups/d, the risk of gastric cancer was lower (OR $=0.79,95 \%$ CI $0.63,0.97, I^{2}=63.8 \%$ for 6 cups (approximately $6 \mathrm{~g}$ ) of green tea intake daily; $P=0.15$ for non-linearity; Fig. 4(a)).

One cohort study ${ }^{(19)}$ and two case-control studies ${ }^{(21,23)}$ were included in the non-linear dose-response analysis for the years of green tea intake and the risk of gastric cancer. There was a non-linear dose-response relationship between the years of green tea intake and the decrease in the risk of gastric cancer incidence with 25 years of green tea intake $(\mathrm{OR}=0.59,95 \% \mathrm{CI} 0.42,0.82$, $I^{2}=1.0 \%$ for 25 years of green tea intake; $P=0.13$ for nonlinearity; Fig. 4(b)).
Three retrospective studies ${ }^{(18,20,30)}$ were included in the non-linear dose-response analysis for the temperature of green tea intake and the risk of gastric cancer. The impact of the green tea drinking temperature on the risk of gastric cancer was not conclusive, but the risk of gastric cancer showed a rising trend with the increase in the green tea drinking temperature ( $P=0.022$ for non-linearity; Fig. $4(\mathrm{c})$ ).

\section{Publication bias}

The publication bias of the included studies was assessed using Begg's test and Egger's test. For the cohort studies, the results of Egger's $(P=0.767)$ and Begg's tests $(P=0.806)$ were not significant. For the case-control studies, the results of Egger's $(P=0.025)$ and Begg's tests $(P=0 \cdot 108)$ were also not significant (see online supplementary material, Fig. S1).

\section{Sensitivity analysis}

A sensitivity analysis investigating the influence of each single study on the gastric cancer risk estimate suggested that the risk estimates were not substantially modified by any single study (see online supplementary material, Fig. S2).

\section{Discussion}

In the present meta-analysis, the results of the casecontrol studies showed that the consumption of a high dose of green tea could reduce the risk of gastric cancer. Based on the dose-response analysis, the risk of gastric cancer showed a gradual decreasing trend with increase in the consumption of green tea; additionally, we found a lower risk of gastric cancer associated with a longer tea drinking experience.

Previous experiments demonstrated that the polyphenols in green tea had antioxidant effects and could suppress the occurrence and development of cancer ${ }^{(4-6)}$. At the cellular level, tea polyphenols can inhibit the growth, reproduction and diffusion of cancers ${ }^{(40)}$. Additionally, several studies reported that $H$. pylori infection was an important risk factor for gastric cancer ${ }^{(41)}$. Importantly, green tea has been shown to possess bacteriostatic and bactericidal effects that reduce the occurrence of gastric cancer caused by $H$. pylori infection ${ }^{(42)}$. However, the combined results of the cohort studies in the present meta-analysis showed that high doses of green tea still cannot be considered to reduce the risk of gastric cancer. Similarly, Galanis et al. ${ }^{(27)}$ believed that drinking green tea might not have an effect on the risk of gastric cancer, although this result might have been obtained because an effective dose was not reached ( $\geq 2 \mathrm{cup} / \mathrm{d}$ for the highest dose group in that study) or the number of cases was too small. Additionally, Tsubono et al. ${ }^{(24)}$ obtained the same conclusion that the consumption of green tea had no impact on the risk of gastric cancer. However, our metaanalysis of the case-control studies indicated that the 
Table 1 Characteristics of studies included in the current meta-analysis of associations of green tea and risk of gastric cancer

\begin{tabular}{|c|c|c|c|c|c|c|c|c|c|c|c|}
\hline Source & $\begin{array}{l}\text { Publication } \\
\text { year }\end{array}$ & Age (years) & Observation year & Country & $\begin{array}{l}\text { Follow-up } \\
\text { period } \\
\text { (years) }\end{array}$ & $\begin{array}{l}\text { Loss to } \\
\text { follow-up } \\
\text { rate (\%) }\end{array}$ & $\begin{array}{l}\text { Population } \\
\text { type }\end{array}$ & $\begin{array}{l}\text { No. of } \\
\text { cases }\end{array}$ & $\begin{array}{l}\text { Total } \\
\text { sample } \\
\text { size }\end{array}$ & $\begin{array}{l}\text { Green tea intake } \\
\text { categories (lowest } v . \\
\text { highest) }\end{array}$ & Adjustment for confounders \\
\hline Wang et al. ${ }^{(18) *}$ & 2015 & NA & Feb 2005-Feb 2010 & China & NA & NA & HB & 160 & 480 & $\geq 35 \mathrm{~g} /$ week v. 0 & NA \\
\hline Nechuta et al..$^{(19)} \dagger$ & 2012 & $40-70$ & 1996-2009 & China & 11 & 0.27 & NA & 293 & 69310 & $\geq 150 \mathrm{~g} /$ month $v .0$ & $\begin{array}{l}\text { Age, marital status, education, occupation, } \\
\text { BMI, exercise, fruit and vegetable intake, } \\
\text { meat intake, diabetes, family history of } \\
\text { digestive system cancer }\end{array}$ \\
\hline Mao et al. ${ }^{(20) *}$ & 2011 & $\begin{array}{l}\text { Cases: } 51 \cdot 5 \\
\text { Controls: } 52 \cdot 3\end{array}$ & Apr 2010-Feb 2011 & China & NA & NA & PB & 200 & 400 & $\geq 150 \mathrm{~g} /$ month $v .0$ & $\begin{array}{l}\text { Age, sex, education level, BMI, annual income, } \\
\text { cancer family history, smoking status, } \\
\text { drinking status }\end{array}$ \\
\hline Hoshiyama et al. $^{(22)} \dagger$ & 2004 & $40-79$ & 1988-1997 & Japan & 9 & NA & NA & 157 & 416 & $\geq 5 \mathrm{cups} / \mathrm{d} v .<1 \mathrm{cup} / \mathrm{d}$ & $\begin{array}{l}\text { Age, smoking status, sex, Helicobacter pylori } \\
\text { infection, history of peptic ulcer, family } \\
\text { history of stomach cancer, educational level, } \\
\text { consumption of rice, miso soup, green/ } \\
\text { yellow vegetables, white vegetables and } \\
\text { fruits, preference for salty foods }\end{array}$ \\
\hline Setiawan et al. ${ }^{(23) \star}$ & 2001 & NA & Jan 1995-Jun 1995 & China & NA & NA & PB & 133 & 566 & $\geq 21$ cups/week v. 0 & $\begin{array}{l}\text { Age, gender, education, BMl, pack-years of } \\
\text { smoking, alcohol drinking }\end{array}$ \\
\hline Tsubono et al. ${ }^{(24)} \dagger$ & 2001 & $\geq 40$ & 1984-1992 & Japan & NA & NA & NA & 419 & 199748 & $\geq 5 \mathrm{cups} / \mathrm{d} v .<1 \mathrm{cup} / \mathrm{d}$ & $\begin{array}{l}\text { Sex, age, type of health insurance, history of } \\
\text { peptic ulcer, cigarette smoking, alcohol } \\
\text { consumption, daily consumption of rice, } \\
\text { consumption of black tea and coffee, meat, } \\
\text { green or yellow vegetables, pickled } \\
\text { vegetables, other vegetables, fruits and } \\
\text { bean-paste soup }\end{array}$ \\
\hline Nagano et al. ${ }^{(25)} \dagger$ & 2001 & $\begin{array}{l}\text { M: } 52 \cdot 8 \\
\text { F: } 56 \cdot 8\end{array}$ & 1979-1994 & Japan & $\begin{array}{l}\text { Approx. } \\
10.5\end{array}$ & $5 \cdot 27$ & NA & 901 & 38540 & $\begin{array}{l}\geq 5 \text { times } / \mathrm{d} v \cdot 0-1 \\
\text { time/d }\end{array}$ & $\begin{array}{l}\text { City, age, gender, radiation exposure, smoking } \\
\text { status, alcohol drinking, BMI, education } \\
\text { level, calendar time }\end{array}$ \\
\hline Huang et al. ${ }^{(26) \star ~}$ & 1999 & $20-79$ & 1990-1995 & Japan & NA & NA & $\mathrm{HB}$ & 887 & 29506 & $>6$ cups $/ \mathrm{d}$ v. 0 & $\begin{array}{l}\text { Age and sex, smoking and drinking were } \\
\text { calculated in male group only }\end{array}$ \\
\hline Galanis et al. ${ }^{(27)} \dagger$ & 1998 & $\geq 18$ & 1975-1994 & $\begin{array}{l}\text { USA } \\
\text { (Hawaii) }\end{array}$ & 14.8 & 6.90 & NA & 108 & 11907 & $\geq 2$ cups $/ d$ v. 0 & $\begin{array}{l}\text { Age, years of education, Japanese place of } \\
\text { birth, gender. Analyses among men were } \\
\text { also adjusted for cigarette smoking and } \\
\text { alcohol intake status }\end{array}$ \\
\hline Inoue et $a l^{(28) \star}$ & 1998 & $\geq 40$ & 1990-1995 & Japan & NA & NA & HB & 893 & 19585 & $\geq 7$ cups/d v. 0 & $\begin{array}{l}\text { Coffee intake, black tea intake, gender, age, } \\
\text { year and season at first hospital visit, } \\
\text { habitual smoking, habitual alcohol drinking, } \\
\text { regular physical exercise, fruit intake, rice } \\
\text { intake, beef intake }\end{array}$ \\
\hline Ji et al. ${ }^{(29) *}$ & 1996 & $20-69$ & Dec 1988-Nov 1989 & China & NA & NA & PB & 1124 & 2575 & $>1200$ g/year v. 0 & $\begin{array}{l}\text { Age, income and education among women; } \\
\text { further adjusted for smoking and alcohol } \\
\text { drinking among men }\end{array}$ \\
\hline Yu et al. ${ }^{(30) \star *}$ & 1995 & $<80$ & Oct 1991-Dec 1993 & China & NA & NA & PB & 711 & 1422 & $\geq 4$ batches $/ \mathrm{d} v \cdot 0$ & $\begin{array}{l}\text { Education, birthplace, alcohol drinking, } \\
\text { cigarette smoking and matched variables }\end{array}$ \\
\hline
\end{tabular}

NA, not available; M, male; F, female; HB, hospital based; PB, population based. ${ }^{*}$ Case-control studies.

†Cohort studies. 
(a)

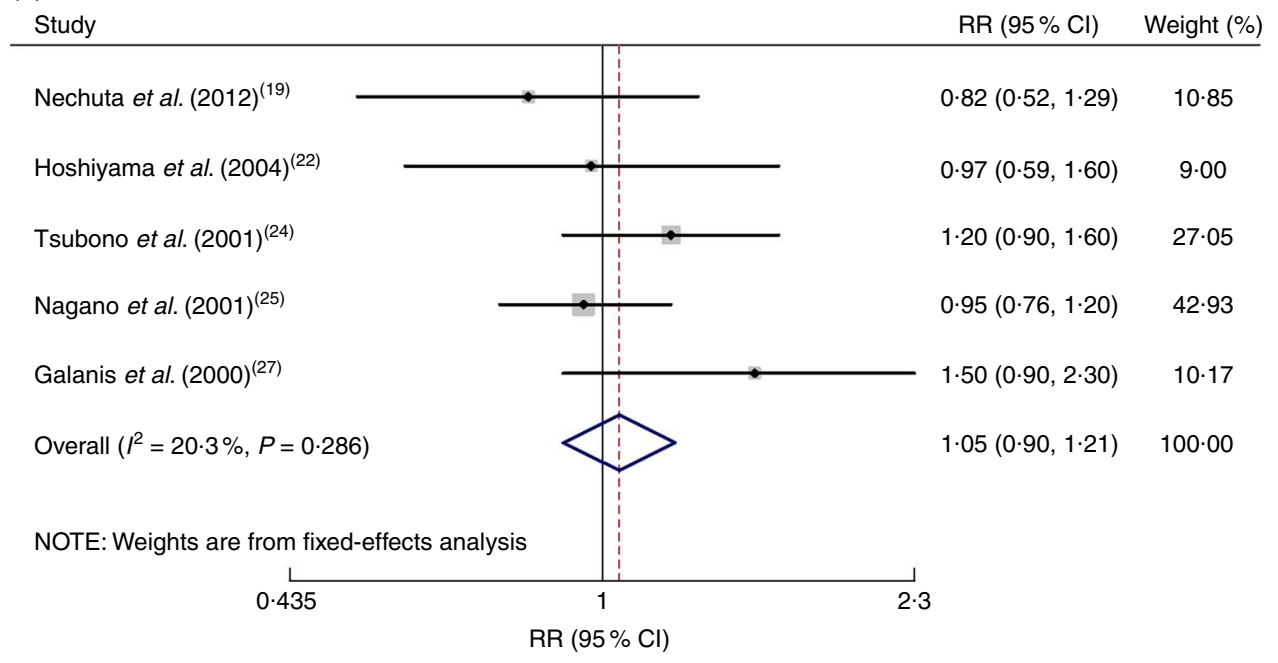

(b)

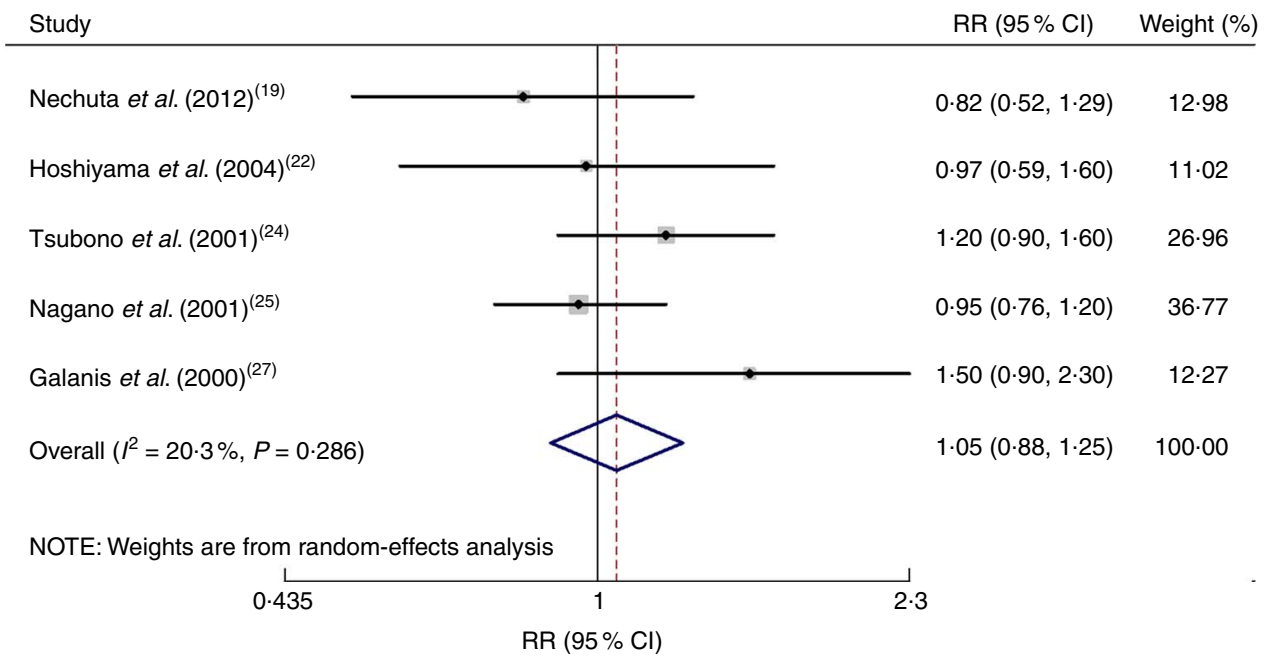

Fig. 2 Meta-analysis of high $v$. low dose of green tea and risk of gastric cancer for cohort studies by using fixed-effects model (a) and random-effects model (b). The study-specific relative risk (RR) and $95 \% \mathrm{Cl}$ are represented by the black dot and horizontal line, respectively; the area of the grey square is proportional to the specific-study weight to the overall meta-analysis. The centre of the open diamond and the dotted vertical line represent the pooled RR; the width of the diamond represents the pooled $95 \% \mathrm{CI}$

consumption of a high dose of green tea could reduce the risk of gastric cancer. The studies conducted by Kono et al., Inoue et al. and Liu et al. showed that exposure to high doses of green tea had a certain impact on the incidence of gastric cancer ${ }^{(21,28,31)}$. Kono et al. ${ }^{(31)}$ believed that the consumption of a high dose of green tea ( $\geq 10 \mathrm{cups} / \mathrm{d}$ ) could reduce the risk of gastric cancer. In their study, a community group in the same area as the hospital-based group was used as the control, and the study subjects from the hospital were surveyed before the diagnosis to reduce recall bias. These case-control studies ${ }^{(21,28,31)}$ included larger sample sizes. Nevertheless, the cohort studies and the case-control studies had different combined results. One possible reason was that the period of green tea exposure was too short or the dose of exposure was too low for the surveyed subjects in the cohort studies.
In Japan, the largest green tea production area is Shizuoka prefecture. A survey found that mortality due to gastric cancer in the local residents of this area was much lower than the average in Japan, which was inferred to be related to green tea consumption by the local residents. Additionally, the local residents not only drank green tea frequently but also frequently replaced the green tea with new tea leaves when drinking, and their history of green tea consumption was very long. Therefore, the reduction of the risk of gastric cancer may be closely related to the dose of the active ingredient in green tea and the length of tea exposure ${ }^{(43)}$. The present meta-analysis found that when the green tea exposure was in a low dose ( $\leq 4 \mathrm{cups} / \mathrm{d}$ ), its protective effect on gastric cancer was not obvious; however, when the exposure dose was higher than $5 \mathrm{cups} / \mathrm{d}$, its protective effect on gastric cancer gradually increased. Wang et al. reported that when the 
(a)

\begin{tabular}{|c|c|c|}
\hline Study & OR $(95 \% \mathrm{Cl})$ & Weight (\%) \\
\hline Wang et al. (2015) $)^{(18)}$ & $0.53(0.23,0.97)$ & $2 \cdot 80$ \\
\hline Mao et al. $(2011)^{(20)}$ & $1 \cdot 14(0 \cdot 72,1 \cdot 82)$ & $6 \cdot 74$ \\
\hline Liu et al. (2010) & $0.25(0.03,0.67)$ & 0.60 \\
\hline Setiawan et al. (2001) $)^{(23)}$ & $0.39(0.15,1 \cdot 01)$ & 1.59 \\
\hline Huang et al. (1999) $)^{(26)}$ & $0.90(0.73,1 \cdot 11)$ & $32 \cdot 98$ \\
\hline Inoue et al. (1998) $)^{(28)}$ & $0.69(0.48,1.00)$ & $10 \cdot 75$ \\
\hline Ji et al. (1996) $)^{(29)}$ & $0.92(0.76,1 \cdot 12)$ & 38.52 \\
\hline Yu et al. (1995) $)^{(30)}$ & $0.54(0.33,0.88)$ & $6 \cdot 02$ \\
\hline Overall $\left(I^{2}=48.3 \%, P=0.060\right)$ & $0.84(0.74,0.95)$ & $100 \cdot 00$ \\
\hline \multicolumn{3}{|l|}{ NOTE: Weights are from fixed-effects analysis } \\
\hline\llcorner & 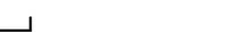 & \\
\hline \multirow[t]{2}{*}{0.03} & 33.3 & \\
\hline & & \\
\hline
\end{tabular}

(b)

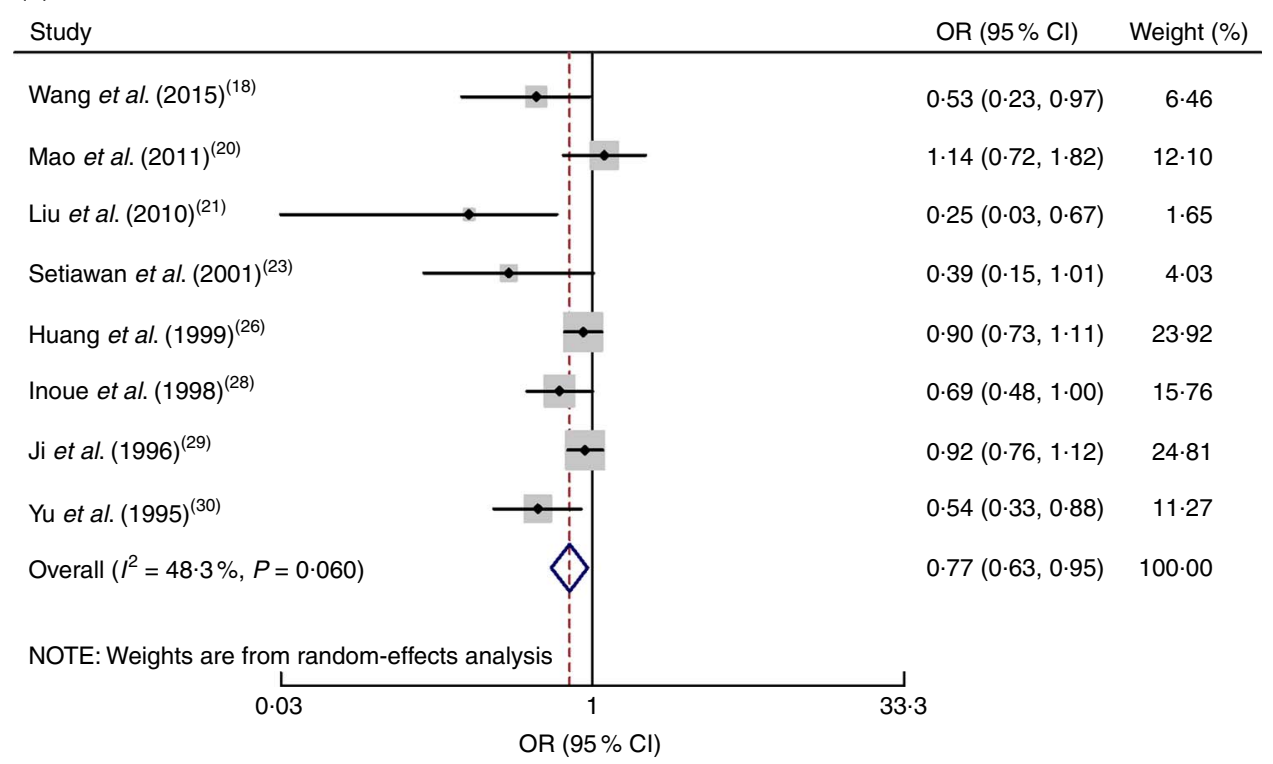

Fig. 3 Meta-analysis of high $v$. low dose of green tea and risk of gastric cancer for case-control studies by using fixed-effects model (a) and random-effects model (b). The study-specific OR and $95 \% \mathrm{Cl}$ are represented by the black dot and horizontal line, respectively; the area of the grey square is proportional to the specific-study weight to the overall meta-analysis. The centre of the open diamond and the dotted vertical line represent the pooled OR; the width of the diamond represents the pooled $95 \% \mathrm{Cl}$

green tea exposure was $\geq 35 \mathrm{~g} /$ month (approximately 5 cups/d), the risk of gastric cancer decreased ${ }^{(18)}$. Additionally, a previous systematic review reported that the intake of a high dose of green tea was a protective factor for the reduction of gastric cancer ${ }^{(44)}$. These findings are consistent with the results of the current meta-analysis. In subjects with a prolonged history of tea consumption, a longer history of green tea exposure had a stronger protective effect on gastric cancer. Liu et al. ${ }^{(21)}$ reported that the risk of gastric cancer was decreased with increasing time of green tea consumption. Studies have confirmed that long-term exposure to polyphenols could help improve the oxidative state of the body, scavenge free radicals, improve local chronic inflammation and regulate the digestive tract microenvironment, thereby contributing to the reduction of the risk of gastric cancer ${ }^{(45-47)}$. Notably, the present metaanalysis found that when the temperature of the tea was too high, the occurrence of gastric cancer could even be promoted with a certain dose-effect relationship. Previous studies have reported that long-term consumption of food at a high temperature might damage the digestive tract mucosa, causing related diseases ${ }^{(10)}$. However, whether high temperatures will lead to gastric cancer needs to be confirmed by further studies with large sample sizes. 

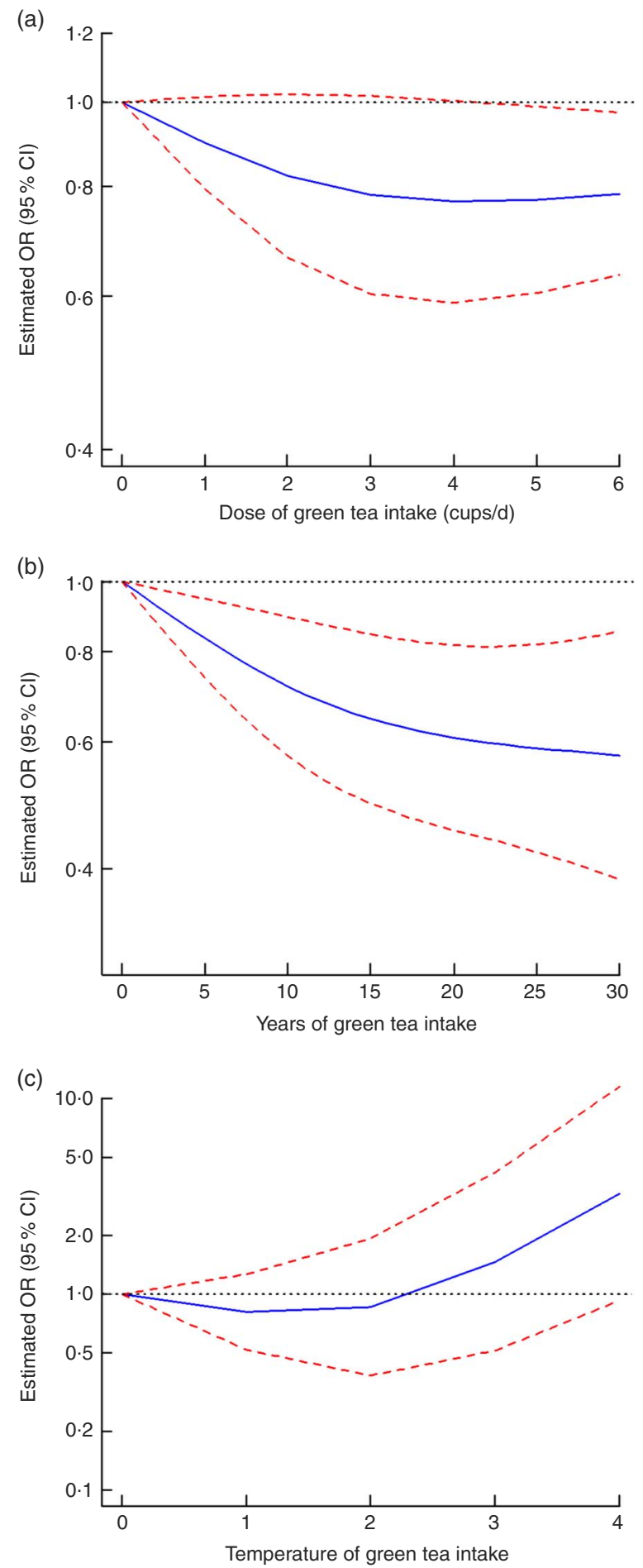

Fig. 4 Non-linear dose-response relationship between dose (a), years (b) and temperature (c) of green tea intake and the risk of gastric cancer: _- best-fitting fractional polynomial; - - - , $95 \% \mathrm{Cl}$. For temperature of green tea intake, 0, 1, 2, 3 and 4 represent undrinkable, cool, warm, hot and very hot, respectively

\section{Other systematic reviews}

Some systematic reviews of tea and gastric cancer exist. First, Zhang et $a l^{(48)}$ included only prospective studies investigating the dose-response association between tea consumption and the incidence of cancer (gastric cancer, rectal cancer, colon cancer, lung cancer, etc.). Their study indicated that increased tea consumption is associated with a reduction in the risk of oral cancer but has no significant effect on the risk of other common cancers. Second, Sasazuki et $a l .{ }^{(49)}$ investigated green tea consumption and gastric cancer risk (incidence and death) among the Japanese population and performed a meta-analysis which included case-control studies and cohort studies. The conclusion was that green tea possibly decreases the risk of gastric cancer in women. Additionally, Boehm et al. ${ }^{(50)}$ conducted a meta-analysis of green tea for the prevention of cancer, including case-control studies, cohort studies and randomized controlled trials. They found moderate to strong evidence that green tea consumption does not decrease the risk of dying due to gastric cancer. Finally, Borrelli et $a l .{ }^{(51)}$ published a systematic review of the association between green tea and gastrointestinal cancer risk in which cross-sectional studies, case-control studies and cohort studies were included. They concluded that an inverse association does not seem to exist between green tea consumption and the risk of gastric and intestinal cancer. Additionally, their study found that the effect of green tea is related to the method of preparation and its strength and temperature, which should be considered in future epidemiological investigations.

Compared with previous meta-analyses, our meta-analysis has some obvious differences. First, herein, we analysed not only the relationship between drinking green tea and the risk of gastric cancer, but also the relationship between the duration (years) of drinking green tea and the temperature of green tea and the risk of gastric cancer. Moreover, we analysed the dose-response relationship to understand the risk of gastric cancer at different levels of exposure. Finally, the exposure factor in our meta-analysis review was green tea, a specific type of tea; thus, the results were more specific, reducing the level of heterogeneity.

\section{Limitations}

The present study has some limitations. First, the scope of the included studies was limited and the research locations were mostly in East Asia, including China and Japan; thus, the study subjects were mostly an Asian population. Second, the original studies reported the tea dose in the unit of 'cups', from which the dosage of the active ingredient in green tea could not be determined. Third, we may have missed some studies because the database searches were limited. Some publication bias may exist in the included case-control studies. Additionally, adjustment for other involved risk factors was limited in the included studies, and some bias might have occurred in their reported risk values. Finally, there are some confounding factors in our study. Different follow-up periods of included studies may lead to a difference in the incidence of gastric cancer and thus have an impact on the true relationship between exposure and outcome. In addition, 
differences in year of publication lead to updates in research methods, improvements in detection methods and changes in dietary habits, resulting in differences in outcome accuracy.

\section{Implications}

The present meta-analysis has important implications for further studies on green tea and gastric cancer risk. In subsequent observational studies, the corresponding study of different races should be increased, the units for measuring tea drinking should be taken into account and the follow-up period should be clearly defined. For the following basic research, we can focus on the effect of tea polyphenols (main active components in green tea) on gastric cancer. In addition, such study can provide a basis for the tea-drinking habits of people, and provide a reference for the production of appropriate nutritional supplements. In the absence of clear evidence answering questions about the right amount, duration (years) and temperature of green tea intake, further high-quality studies are needed to make concrete public recommendations.

\section{Conclusion}

In summary, long-term and high-dose consumption of green tea may be associated with a reduced risk of gastric cancer. In addition, drinking too-high-temperature green tea may be associated with an increased risk of gastric cancer, but it is still unclear whether high-temperature green tea is a risk factor for gastric cancer. However, the duration of follow-up in uncertain, which raises concerns regarding the precision of our analysis. Additional research including large-scale pooling and high-quality studies will be needed to confirm our conclusions.

\section{Acknowledgements}

Financial support: This work was funded by the National Natural Science Foundation of China (NSFC; grant number 81473068) and the National Social Science Foundation (China) (NSSF; grant number 14BTJ019). The NSFC and NSSF had no role in the design, analysis or writing of this article. Conflict of interest: None. Authorship: Y.H.H. and H.R.C. contributed equally to this work. Y.H.H. and L.Z. conceived the study. Y.H.H. and H.R.C. searched the databases and checked them according to the eligibility and exclusion criteria. L.Z. helped develop search strategies. L.Z. gave advice on meta-analysis methodology. G.M.L. helped extract quantitative data from some papers. Y.H.H., H.R.C. and L.Z. analysed the data. Y.H.H. wrote the draft of the paper. Y.H.H., H.R.C., L.Z., G.M.L. and D.L.Y. contributed to writing, reviewing or revising the paper. All authors approved the final version. D.Y. is the guarantor. Ethics of human subject participation: Ethical approval was not required.

\section{Supplementary material}

To view supplementary material for this article, please visit https://doi.org/10.1017/\$1368980017002208

\section{References}

1. Hajra NG \& Yang CWM (2015) Diversification of the tea products - global scenario. J Tea Sci Res 5, 1-10.

2. Lin YS, Tsai YJ, Tsay JS et al. (2003) Factors affecting the levels of tea polyphenols and caffeine in tea leaves. J Agric Food Chem 51, 1864-1873.

3. Zhang XM, Ni Y \& Li XR (2013) Advances in study on pharmacological effects of tea polyphenol. Drug Eval Res 36, 157-160.

4. Wang D, Wang Y, Wan X et al. (2015) Green tea polyphenol (-)-epigallocatechin-3-gallate triggered hepatotoxicity in mice: responses of major antioxidant enzymes and the Nrf2 rescue pathway. Toxicol Appl Pharmacol 283, 65-74.

5. Srivastava AK, Bhatnagar P, Singh M et al. (2013) Synthesis of PLGA nanoparticles of tea polyphenols and their strong in vivo protective effect against chemically induced DNA damage. Int J Nanomed 8, 1451-1462.

6. Zhong W, Huan XD, Cao Q et al. (2015) Cardioprotective effect of epigallocatechin-3-gallate against myocardial infarction in hypercholesterolemic rats. Exp Ther Med $\mathbf{9}$, 405-410.

7. Kim HS, Quon MJ \& Kim JA (2014) New insights into the mechanisms of polyphenols beyond antioxidant properties; lessons from the green tea polyphenol, epigallocatechin 3-gallate. Redox Biol 2, 187-195.

8. Weinreb O, Mandel S, Amit T et al. (2004) Neurological mechanisms of green tea polyphenols in Alzheimer's and Parkinson's diseases. J Nutr Biochem 15, 506-516.

9. Basu A \& Lucas EA (2007) Mechanisms and effects of green tea on cardiovascular health. Nutr Rev 65, 361-375.

10. Goldman L \& Schafer AI (2015) Goldman-Cecil Medicine. Amsterdam: Elsevier.

11. Compare D, Rocco A \& Nardone G (2010) Risk factors in gastric cancer. Eur Rev Med Pharmacol Sci 14 , 302-308.

12. Zhang ZF, Kurtz RC, Yu GP et al. (1997) Adenocarcinomas of the esophagus and gastric cardia: the role of diet. Nutr Cancer 27, 298-309.

13. Zhou Y, Du WD, Chen G et al. (2012) Association analysis of genetic variants in microRNA networks and gastric cancer risk in a Chinese Han population. $J$ Cancer Res Clin Oncol 138, 939-945.

14. Ferlay J, Soerjomataram I, Dikshit R et al. (2015) Cancer incidence and mortality worldwide: sources, methods and major patterns in GLOBOCAN 2012. Int J Cancer 136, E359-E386.

15. Bray F, Ren JS, Masuyer E et al. (2013) Global estimates of cancer prevalence for 27 sites in the adult population in 2008. Int I Cancer 132, 1133-1145.

16. Kamangar F, Dores GM \& Anderson WF (2006) Patterns of cancer incidence, mortality, and prevalence across five continents: defining priorities to reduce cancer disparities in different geographic regions of the world. J Clin Oncol 24, 2137-2150.

17. Ferlay J, Shin HR, Bray F et al. (2010) Estimates of worldwide burden of cancer in 2008: GLOBOCAN 2008. Int J Cancer 127, 2893-2917.

18. Wang Y, Duan H \& Yang H (2015) A case-control study of stomach cancer in relation to Camellia sinensis in China. Surg Oncol 24, 67-70.

19. Nechuta S, Shu XO, Li HL et al. (2012) Prospective cohort study of tea consumption and risk of digestive system 
cancers: results from the Shanghai Women's Health Study. Am J Clin Nutr 96, 1056-1063.

20. Mao XQ, Jia XF, Zhou G et al. (2011) Green tea drinking habits and gastric cancer in southwest China. Asian Pac J Cancer Prev 12, 2179-2182.

21. Liu AM, Zhao JK \& Zhang ZF (2010) Case-control study of the effect of drinking green tea on incidence of stomach cancer in residents in Dafeng City, Jiangsu Province. China Cancer 19, 585-588.

22. Hoshiyama Y, Kawaguchi T, Miura Y et al. (2004) A nested case-control study of stomach cancer in relation to green tea consumption in Japan. Br J Cancer 90, 135-138.

23. Setiawan VW, Zhang ZF, Yu GP et al. (2001) Protective effect of green tea on the risks of chronic gastritis and stomach cancer. Int J Cancer 92, 600-604.

24. Tsubono Y, Nishino Y, Komatsu S et al. (2001) Green tea and the risk of gastric cancer in Japan. $N$ Engl J Med $\mathbf{3 4 4}$, 632-636.

25. Nagano J, Kono S, Preston DL et al. (2001) A prospective study of green tea consumption and cancer incidence, Hiroshima and Nagasaki (Japan). Cancer Causes Control 12, 501-508.

26. Huang X, Tajima K, Hamajima N et al. (1999) Effect of life styles on the risk of subsite-specific gastric cancer in those with and without family history. J Epidemiol 9, 40-45.

27. Galanis DJ, Kolonel LN, Lee J et al. (1998) Intakes of selected foods and beverages and the incidence of gastric cancer among the Japanese residents of Hawaii: a prospective study. Int J Epidemiol 27, 173-180.

28. Inoue M, Tajima K, Hirose $\mathrm{K}$ et al. (1998) Tea and coffee consumption and the risk of digestive tract cancers: data from a comparative case-referent study in Japan. Cancer Causes Control 9, 209-216.

29. Ji BT, Chow WH, Yang G et al. (1996) The influence of cigarette smoking, alcohol, and green tea consumption on the risk of carcinoma of the cardia and distal stomach in Shanghai, China. Cancer 77, 2449-2457.

30. Yu GP, Hsieh CC, Wang LY et al. (1995) Green-tea consumption and risk of stomach cancer: a population-based case-control study in Shanghai, China. Cancer Causes Control 6, 532-538.

31. Kono S, Ikeda M, Tokudome S et al. (1998) A case-control study of gastric cancer and diet in Northern Kyushu. Jpn J Cancer Res 79, 1067-1074.

32. Sasazuki S, Inoue M, Hanaoka T et al. (2004) Green tea consumption and subsequent risk of gastric cancer by subsite: the JPHC Study. Cancer Causes Control 15, 483-491.

33. Yu SZ, Zhang ZF, Yu GP et al. (2001) Epidemiological study of the influence of drinking green tea on gastric cancer and chronic gastritis incidence. China Oncol 11, 42-46.

34. Stang A (2010) Critical evaluation of the NewcastleOttawa scale for the assessment of the quality of nonrandomized studies in meta-analyses. Eur J Epidemiol 25, 603-605.

35. Wells GA, Shea B, O'Connell D et al. (2000) The NewcastleOttawa Scale (NOS) for assessing the quality of nonrandomised studies in meta-analyses. http://www. ohri.ca/programs/clinical_epidemiology/oxford.htm (accessed January 2016).
36. Higgins JP \& Thompson SG (2002) Quantifying heterogeneity in a meta-analysis. Stat Med 21, 1539-1558.

37. Harrell FE Jr, Lee KL \& Pollock BG (1988) Regression models in clinical studies: determining relationships between predictors and response. J Natl Cancer Inst 80, 1198-1202.

38. Aune D, Greenwood DC, Chan DS et al. (2011) Body mass index, abdominal fatness and pancreatic cancer risk: a systematic review and non-linear dose-response metaanalysis of prospective studies. Ann Oncol 23, 843-852.

39. Li ZG, Shimada Y, Sato F et al. (2003) Promotion effects of hot water on $N$-nitrosomethylbenzylamine-induced esophageal tumorigenesis in F344 rats. Oncol Rep 10, 421-426.

40. Qiao JP, Gu CX, Shang WH et al. (2011) Effect of green tea on pharmacokinetics of 5-fluorouracil in rats and pharmacodynamics in human cell lines in vitro. Food Chem Toxicol 49, 1410-1415.

41. World Health Organization \& International Agency for Research on Cancer (1994) IARC Monographs on the Evaluation of Carcinogenic Risks to Humans. vol. 61: Schistosomes, Liver Flukes and Helicobacter pylori, pp. 177-240. Lyon: IARC.

42. Jeong M, Park JM, Han YM et al. (2016) Dietary intervention of artemisia and green tea extracts to rejuvenate Helicobacter pylori-associated chronic atrophic gastritis and to prevent tumorigenesis. Helicobacter 21, 40-59.

43. Oguni I NK, Kanaya S, Ota Y et al. (1989) Epidemiological and experimental studies on the antitumor activity by green tea extracts. Jpn J Nutr $\mathbf{4 7}, 93-102$.

44. Huang DB, Wang W, Shen G et al. (2014) Green tea consumption and risk of gastric cancer in East Asians: a metaanalysis. Chin J Clin Health 17, 30-32.

45. Riegsecker S, Wiczynski D, Kaplan MJ et al. (2013) Potential benefits of green tea polyphenol EGCG in the prevention and treatment of vascular inflammation in rheumatoid arthritis. Life Sci $\mathbf{9 3}, 307-312$.

46. van Duynhoven J, Vaughan EE, van Dorsten F et al. (2013) Interactions of black tea polyphenols with human gut microbiota: implications for gut and cardiovascular health. Am J Clin Nutr 98, 6 Suppl., 1631S-1641S.

47. Kim J, Formoso G, Li YH et al. (2007) Epigallocatechin gallate, a green tea polyphenol, mediates NO-dependent vasodilation using signaling pathways in vascular endothelium requiring reactive oxygen species and Fyn. $J$ Biol Chem 282, 13736-13745.

48. Zhang YF, Xu Q, Lu J et al. (2015) Tea consumption and the incidence of cancer: a systematic review and meta-analysis of prospective observational studies. Eur J Cancer Prev 24, 353-362.

49. Sasazuki S, Tamakoshi A, Matsuo K et al. (2012) Green tea consumption and gastric cancer risk: an evaluation based on a systematic review of epidemiologic evidence among the Japanese population. Jpn J Clin Oncol 42, 335-346.

50. Boehm K, Borrelli F, Ernst E et al. (2009) Green tea (Camellia sinensis) for the prevention of cancer. Cochrane Database Syst Rev issue 3, CD005004.

51. Borrelli F, Capasso R, Russo A et al. (2004) Systematic review: green tea and gastrointestinal cancer risk. Aliment Pharmacol Ther 19, 497-510. 